\title{
Letter \\ CYP2D6 variants and the prediction of tamoxifen response in randomized patients: authors' response
}

\author{
Pia P Wegman and Sten Wingren
}

Department of Biomedicine and Surgery, Division of Cell Biology, Faculty of Health Sciences, Linköping, Sweden

Corresponding author: Pia P Wegman, piapa@ibk.liu.se

Published: 29 September 2005

Breast Cancer Research 2005, 7:E7 (DOI 10.1186/bcr1326)

This article is online at http://breast-cancer-research.com/content/7/6/E7

(c) 2005 BioMed Central Ltd

See related research by Wegman et al. in issue 7.3 [http://breast-cancer-research.com/content/7/3/R284]

and letter by Rae et al. online [http://breast-cancer-research.com/content/7/5/E6]

Rae and coworkers [1] argued that there may be selection bias in our recently published study [2] and that, in fact, our findings are consistent with their previously reported data.

Our study (hereafter referred to as the 'current study') [2] was conducted to validate whether polymorphisms in genes that encode metabolic enzymes may predict the response to tamoxifen among oestrogen receptor (ER)-positive postmenopausal breast cancer patients randomly assigned to treatment with or without tamoxifen. The initial trial was begun in 1976 in Stockholm, Sweden and patient material from approximately one-third of the initial population was available for use in the current study. In the Materials and method section of the report we compared characteristics such as lymph node status, ER status and tumour size between the initial and current study populations, and found that these parameters were similarly distributed throughout the populations. However, despite these similarities, selection bias could not be completely excluded, and this was noted in our conclusion, as was the need for confirmation of our findings in a larger randomized trial.

Initially, we assessed possible differences in prognostic value between genotypes of CYP2D6 and SULT1A1 in the study population (including both ER-negative and ER-positive patients). However, the primary aim was to investigate whether these genotypes could predict response to tamoxifen therapy in ER-positive patients. Strikingly, patients with different CYP2D6 genotypes responded differently to therapy. We found no variation in distant recurrence-free survival among homozygous carriers of the CYP2D6*1 allele, but a significant difference was noted in carriers of the CYP2D6*4 allele. Recently, Nowell and coworkers [3] conducted a similar study in which they investigated the same CYP2D6 polymorphism in patients either receiving or not receiving tamoxifen treatment. They found that the CYP2D6*4 variant allele appeared to be associated with decreases in death and recurrence rates. To our knowledge, no previous studies have been performed to elucidate the predictive value of CYP2D6 genotypes on tamoxifen treatment.

Rae and colleagues [1] interpret our data as consistent with their findings, suggesting that CYP2D6 poor metabolizers may derive less benefit from tamoxifen treatment. We disagree with that view. In support of their conclusion, Dr Rae and colleagues cite a meeting abstract of a study in which all patients were treated with tamoxifen and were not randomized according to tamoxifen treatment [4]. Our analysis represents a different comparison than that reported by Goetz and coworkers because, even though the sample population sizes are similar, result interpretation is highly dependent on randomization and study design. In our opinion we cannot endorse Dr. Rae's statement that our findings are consistent with their data.

\section{Competing interests}

The author(s) declare that they have no competing interests.

\section{References}

1. Rae JM, Goetz MP, Hayes DF, Ingle JN, Li L, Storniolo AM, Stearns V, Flockhart DA: CYP2D6 genotype and tamoxifen response. Breast Cancer Res 2005, 7:E6.

2. Wegman P, Vainikka L, Stål O, Nordenskjöld B, Skoog L, Rutqvist L-E, Wingren S: Genotype of metabolic enzymes and the benefit of tamoxifen in postmenopausal breast cancer patients. Breast Cancer Res 2005, 7:R284-R290.

3. Nowell SA, Ahn J, Rae JM, Scheys JO, Trovato A, Sweeney C, MacLeod SL, Kadlubar FF, Ambrosone CB: Association of genetic variation in tamoxifen-metabolizing enzymes with overall survival and recurrence of disease in breast cancer patients. Breast Cancer Res Treat 2005, 91:249-258.

4. Goetz MP, Rae JM, Suman VJ, Safgren SL, Ames MM, Vissche DW, Flockhart DA, Adjei AA, Weinshilboum RM, Couch FJ, et al.: Pharmacogenomic determinants of outcome with tamoxifen therapy: findings from the randomized North Central Cancer Treatment Group adjuvant breast cancer trial 89-30-52. Breast Cancer Res Treat 2004, 88:S35. 